\title{
01.1;04.4
}

\section{Потоки пылевых частиц в системе Марса}

\author{
(ㄷ С.И. Попель, А.П. Голубь, Г.Г. Дольников, А.В. Захаров, А.А. Карташева
}

Институт космических исследований РАН, Москва, Россия

E-mail: serg.i.popel@gmail.com

Поступило в Редакцию 25 февраля 2020 г.

В окончательной редакции 25 февраля 2020 г.

Принято к публикации 18 мая 2020г.

Вычислены потоки массы и пылевых частиц, появление которых на орбите вокруг Марса обусловлено процессами столкновений метеороидов с Фобосом и Деймосом. Определены распределения по размерам захваченных на орбите вокруг Марса пылевых частиц. Знание о параметрах этих частиц важно при планировании экспериментов по исследованию пыли в системе Марса в рамках будущих космических миссий.

Ключевые слова: будущие космические миссии, Марс, Фобос, Деймос, пылевые частицы, пылевая плазма, пьезоэлектрический ударный сенсор, зарядочувствительная сетка.

DOI: 10.21883/PJTF.2020.16.49851.18264

В настоящее время существенное внимание уделяется исследованию системы Марса космическими аппаратами, такими как Mars Express, ExoMars Trace Gas Orbiter и др. В рамках готовящейся миссии „Бумеранг“ („Фобос-Грунт-2“) предполагается обнаружение пылевых частиц на орбите вокруг Марса, а также определение основных параметров пылевых частиц (импульса, массы, скорости, заряда) у одного из его спутников. Согласно имеющимся наблюдениям (см., например, [1,2]), поверхность спутников Марса (Фобоса и Деймоса) покрыта пылью, которая состоит из несвязанных друг с другом небольших крупинок реголита, образовавшегося в результате метеороидной бомбардировки. Можно ожидать, что из-за слабой гравитации на Фобосе и Деймосе гравитационные поля спутников Марса будут преодолены достаточно большим количеством пылевых частиц, имеющих скорости, бо́льшие второй космической скорости (для Фобоса $11 \mathrm{~m} / \mathrm{s}$, для Деймоса $5.6 \mathrm{~m} / \mathrm{s}$ ). Данные частицы могут оказаться захваченными на орбите вокруг Mapca. Знание о параметрах этих частиц весьма важно при планировании будущей миссии „Бумеранг“.

В рамках этой миссии для исследования пыли предполагается использовать пьезоэлектрические ударные сенсоры и зарядочувствительные сетки (рис. 1). Работа пьезоэлектрических ударных сенсоров основана на ударном воздействии пылевой частицы, зарядочувствительная сетка позволяет обнаружить индукционный сигнал при прохождении через нее заряженной пылевой частицы при условии, что заряд частицы оказывается больше $10^{3} e$, где $e-$ элементарный заряд. Когда пылевая частица достигает пьезоэлектрического датчика, генерируется электрический сигнал с амплитудой, пропорциональной импульсу пылевой частицы. Задержка между сигналом от пьезоэлектрических датчиков и сигналом от зарядочувствительной сетки позволяет определить скорость пылевой частицы и рассчитать ее массу.
Фобос и Деймос представляют собой безатмосферные космические тела. Пыль над спутниками Марса является компонентом пылевой плазмы (см., например, $[3,4]$ ). Подобно ситуации у Луны [5,6] при отрыве пылевых частиц от поверхностей спутников Марса существенную роль играют удары метеороидов. В настоящей работе вычисляются потоки массы и пылевых частиц, появление которых на орбите вокруг Марса обусловлено процессами столкновений метеороидов с Фобосом и Деймосом. Кроме того, определяются распределения по размерам захваченных на орбите вокруг Марса пылевых частиц.

Количество ударов метеороидов о поверхности Фобоса и Деймоса определяется значениями их потока. Здесь используются зависимости [7], характеризующие плотность потока метеороидов, в частности, для ситуации, соответствующей рис. 2 из работы [7]. При соударении метеороида с поверхностью спутника Марса происходит сильное сжатие и нагрев вещества ударника и мишени. В результате образуется сильная ударная волна, распространяющаяся (и ослабевающая при движении) от точки удара. Высокая плотность энергии делает удар в значительной степени подобным взрыву.

Вычисления проводятся для ситуации, когда ударник состоит из сплошного габброидного анортозита, тогда как веществом мишени является пористый габброидный анортозит. Предполагается, что плотности ударника и мишени до соударения соответственно равны $\rho_{i 0}=3 \mathrm{~g} / \mathrm{cm}^{3}$ и $\rho_{t 0}=1.4 \mathrm{~g} / \mathrm{cm}^{3}$. Плотность вещества частиц реголита составляет $\rho_{t 00}=3 \mathrm{~g} / \mathrm{cm}^{3}$. Концентрация частиц реголита равна $n_{r e g}=800 \mathrm{~cm}^{-3}$. Пористость мишени $k=\rho_{t 00} / \rho_{t 0}=2.14$. Также предполагается линейная зависимость между скоростью сильной ударной волны $D_{i, t}$ и массовой скоростью $u$ за ударно-волновым фронтом: $D_{i, t}=C_{i, t}+S_{i, t} u$. Здесь индексы $i, t$ характеризуют вещество ударника и мишени соответственно, 

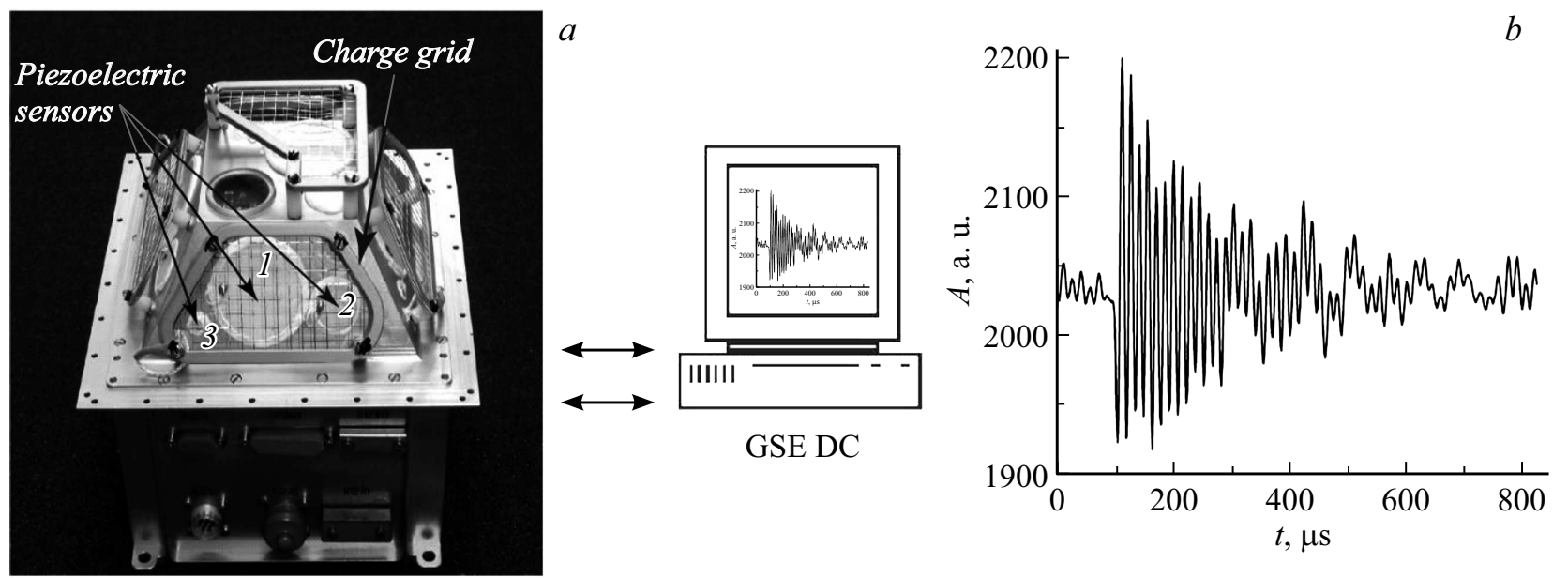

Рис. 1. Схема прибора и измерений для исследования пыли в системе Марса. $a$ - фотография прибора, отмечены пьезоэлектрические ударные сенсоры и зарядочувствительная сетка; $b$ - типичный электрический сигнал, генерируемый при ударном воздействии пылевой частицы.

$C_{i}=7.71 \mathrm{~km} / \mathrm{s}, S_{i}=1.05, C_{t}=C_{i} k /\left(1+S_{i}(k-1)\right)=7.51 \mathrm{~km} / \mathrm{s}$, $S_{t}=S_{i} k /\left(1+S_{i}(k-1)\right)=1.02$. Скорость ударной волны и массовая скорость однозначно определяют уравнение состояния через хорошо известные уравнения Гюгонио. Линейная зависимость между указанными скоростями обычно достаточно хорошо описывает экспериментальные данные (см. [8]). В звуковой волне максимальное давление $p_{m}$ и максимальная массовая скорость $u_{m}$ за ее фронтом прямо пропорциональны друг другу: $p_{m}=p_{t 0} c_{0} u_{m}$, где $c_{0}-$ скорость звука в невозмущенном реголите, для которой используется значение $c_{0}=300 \mathrm{~m} / \mathrm{s}$ по аналогии с сухим песком [9].

Вокруг эквивалентного центра метеороидного взрыва, расположенного на определенной глубине под поверхностью, формируются зоны (ср. с $[5,6])$, характеризующие происходящие при этом процессы: зона испарения вещества (I), зона плавления вещества (II), зона разрушения частиц, составляющих лунный реголит, и их необратимых деформаций (III), а также зона нелинейных упругих деформаций вещества реголита (IV), характеризуемая значениями давления в нелинейной звуковой волне, меньшими динамического предела упругости. За зоной IV находится зона линейных упругих деформаций $(\mathrm{V})$, в которой звуковая волна может рассматриваться как линейная. На границах между выделенными зонами массовая скорость за фронтом ударной волны принимает значения $6,1.5,0.6$ и $0.3 \mathrm{~km} / \mathrm{s}$ соответственно.

При распространении ударной волны в грунте спутника Марса и выходе ее на свободную поверхность происходит выброс в свободное пространство вещества со скоростью, равной массовой скорости за фронтом ударной волны. Исходя из выражений для глубины откольного слоя (см., например, $[5,6,10])$, т.е. слоя, в котором фрагменты с поверхности породы спутника Марса отделяются в результате взаимодействия с волной сжатия, и среднего потока метеороидов на поверх- ности Фобоса или Деймоса, можно найти количество пылевых частиц, поднимающихся в единицу времени над единицей площади поверхности спутника Марса вследствие ударов метеороидов.

Отметим, что вещество, выбрасываемое ударной волной из зон I-IV, а также из части зоны V, имеет скорость больше второй космической скорости для спутников Марса и таким образом преодолевает гравитационное поле Фобоса или Деймоса. Если при этом скорость вещества относительно Марса оказывается меньше второй космической скорости для Марса на расстоянии орбиты спутника планеты (равной $3.02 \mathrm{~km} / \mathrm{s}$ для орбиты Фобоса и $1.91 \mathrm{~km} / \mathrm{s}$ для орбиты Деймоса), то выбрасываемое с поверхности спутников вещество оказывается захваченным на орбите вокруг Марса.

Из зоны плавления вещества (II) ударной волной выбрасывается в свободное пространство материал, который представляет собой жидкость, распадающуюся на фрагменты [7]. Образуются равновесные капли, которые, удаляясь от поверхности спутника Марса, затвердевают. Согласно $[6,11]$, равновесное значение радиуса капли (при $t \rightarrow \infty)$, образованной (вследствие удара метеороида) в зоне плавления вещества (II), имеет вид $r_{\infty}=a=\left(15 \sigma C_{D} / 4 \rho_{d} a_{0}\right)^{1 / 2}$, где $\sigma-$ коэффициент поверхностного натяжения жидкой капли (для силикатных частиц обычно $\left.\sigma \sim 0.3 \mathrm{~N} \cdot \mathrm{m}^{-1}\right), C_{D}$ - коэффициент сопротивления при движении капли в паровом потоке, $\rho_{d}$ - плотность вещества капли, $a_{0}$ - модуль вектора ускорения, $\mathbf{a}_{0}=-(1 / \rho) \nabla P, \rho-$ плотность капельнопаровой смеси, $\nabla P$ - градиент давления $P$. Вычисляя градиент давления для параметров ударной волны, образованной в результате удара высокоскоростного метеороида, и полагая, что $C_{D}=1$ (см. [11]), $\rho_{d}=3 \mathrm{~g} / \mathrm{cm}^{3}$, $\sigma=0.3 \mathrm{~N} \cdot \mathrm{m}^{-1}$, находим характерный радиус капли: $a \approx 1.5 \cdot 10^{-4} a_{i}^{1 / 2}$, где $a$ и $a_{i}$ вычисляются в $\mathrm{cm}$. 


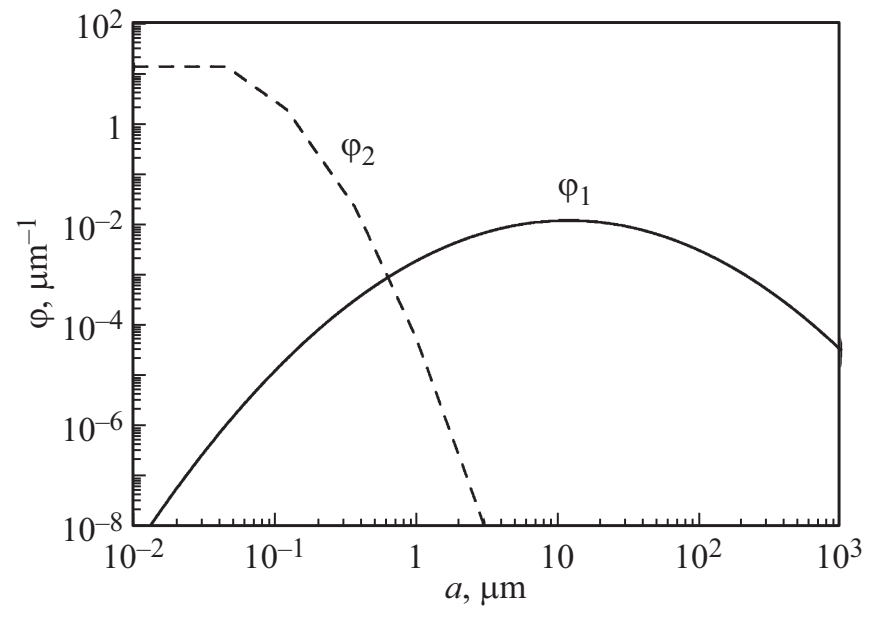

Рис. 2. Нормированные на единицу распределения по размерам частиц нерасплавленного реголита (сплошная кривая) и затвердевших капель (штриховая кривая), захваченных на орбите вокруг Марса и имеющих происхождение на его спутниках Фобосе и Деймосе.

На основе вычислений скорости и количества вещества, поднимающегося над поверхностью спутников Марса и происходящего из различных зон, удается сформулировать следующие выводы.

Основная масса захватываемого на орбите вокруг Марса вещества, выбрасываемого с поверхности спутников планеты при метеороидных ударах, поступающего из зоны $\mathrm{V}$ линейных упругих деформаций, по массе примерно в 40 раз больше, чем из всех других вместе взятых зон (I-IV).

Расплавленное вещество, выбрасываемое из зоны II в свободное пространство, распадается на капли, которые впоследствии затвердевают и становятся пылевыми частицами. Число таких частиц (из-за их малого размера) значительно больше числа захваченных на орбите вокруг Марса частиц нерасплавленного реголита (из зон III-V).

Потоки массы, а также количества частиц нерасплавленного реголита и затвердевших капель, захваченных на орбите вокруг Марса, составляют соответственно примерно $20 \mathrm{~g} / \mathrm{s}, 10^{4} \mathrm{~s}^{-1}$ и $10^{12} \mathrm{~s}^{-1}$ для вещества от Фобоса и $10 \mathrm{~g} / \mathrm{s}, 0.6 \cdot 10^{4} \mathrm{~s}^{-1}$ и $10^{11} \mathrm{~s}^{-1}$ для вещества от Деймоса.

Распределения пылевых частиц по размерам $a$ на орбите вокруг Марса приобретают вид, показанный на рис. 2. Распределение $\varphi_{1}$ частиц нерасплавленного реголита, захваченных на орбите вокруг Марса, в значительной степени такое же, как и частиц реголита на поверхностях спутников Марса. Верхний предел распределения $\varphi_{2}$ затвердевших капель обусловлен существованием верхнего предела статистических данных по размерам для достаточно мелких метеороидов (см., например, [7]). Размеры капель, существенно бо́льшие $1 \mu \mathrm{m}$, соответствуют размерам метеороидов, превосходящим $1 \mathrm{~cm}$.
Для крупных метеороидов однозначную статистику по размерам построить не удается. Поэтому возможным оказывается лишь построение распределения по размерам сферул, имеющих микронные и субмикронные размеры.

Что касается зарядов пылевых частиц, их величина зависит от размера частицы и условий, в которых она находится. Для оценки заряда частицы $q_{d}$ можно использовать зондовую модель [12]: $q_{d} \sim a T_{e} / e$, где $T_{e}-$ температура электронов солнечного ветра. Для микрометровых частиц $(a \sim 1 \mu \mathrm{m})$ и $T_{e}=1.4 \cdot 10^{5} \mathrm{~K}$ имеем $q_{d} \sim 1 \mathrm{fC}>10^{3} e$. Таким образом, использование зарядочувствительной сетки оправдано при детектировании как микрометровых частиц, так и частиц бо́льших размеров (для которых значения $q_{d}$ оказываются больше).

\section{Финансирование работы}

Работа выполнена при частичной поддержке Российского фонда фундаментальных исследований (проект № 18-02-00341-a).

\section{Конфликт интересов}

Авторы заявляют, что у них нет конфликта интересов.

\section{Список литературы}

[1] Thomas P. // Icarus. 1979. V. 40. N 2. P. 223-243.

[2] Thomas P., Veverka J. // Icarus. 1980. V. 42. N 2. P. 234-250.

[3] Попель С.И., Голубь А.П., Захаров А.В., Зеленый Л.М. // Письма в ЖЭТФ. 2017. Т. 106. В. 8. С. 469-475.

[4] Попель С.И., Голубь А.П., Зеленый Л.М. // Физика плазмы. 2018. T. 44. № 8. С. 635-641.

[5] Попель С.И., Голубь А.П., Лисин Е.А., Извекова Ю.Н., Атаманюк Б., Дольников Г.Г., Захаров А.В., Зеленый Л.М. // Письма в ЖЭТФ. 2016. Т. 103. В. 9. С. 641-646.

[6] Попель С.И., Голубь А.П., Зеленый Л.М., Хораньи М. // Письма в ЖЭТФ. 2017. Т. 105. В. 10. С. 594-599.

[7] Drolshagen G., Dikarev V., Landgraf M., Krag H., Kuiper W. // Earth Moon Planets. 2008. V. 102. N 1-4. P. 191 197.

[8] Мелош Г. Образование ударных кратеров. М.: Мир, 1994. $336 \mathrm{c}$.

[9] Цветков В.М. // Журн. прикл. механики и техн. физики. 1963. № 5. C. 150-157.

[10] Адушкин В.В., Спивак А.А. Подземные взрывы. М.: Наука, 2007. $585 \mathrm{c}$.

[11] Melosh H.J., Vickery A.M. // Nature. 1991. V. 350. N 6318. P. 494-497.

[12] Barnes M.S., Keller J.H., Forster J.C., O’Neill J.A., Coultas D.K. // Phys. Rev. Lett. 1992. V. 68. N 3. P. 313316. 